\title{
Genetic Deletion of gadd45b, a Regulator of Active DNA Demethylation, Enhances Long-Term Memory and Synaptic Plasticity
}

\author{
Faraz A. Sultan, ${ }^{1}$ Jing Wang, ${ }^{1}$ Jennifer Tront, ${ }^{2}$ Dan A. Liebermann, ${ }^{2}$ and J. David Sweatt ${ }^{1}$ \\ ${ }^{1}$ Department of Neurobiology and Evelyn F. McKnight Brain Institute, University of Alabama at Birmingham, Birmingham, Alabama 35294 and ${ }^{2}$ Fels \\ Institute for Cancer Research and Molecular Biology, Temple University, Philadelphia, Pennsylvania 19140
}

Dynamic epigenetic mechanisms including histone and DNA modifications regulate animal behavior and memory. While numerous enzymes regulating these mechanisms have been linked to memory formation, the regulation of active DNA demethylation (i.e., cytosine-5 demethylation) has only recently been investigated. New discoveries aim toward the Growth arrest and DNA damageinducible 45 (Gadd45) family, particularly Gadd45b, in activity-dependent demethylation in the adult CNS. This study found memoryassociated expression of gadd $45 \mathrm{~b}$ in the hippocampus and characterized the behavioral phenotype of $\mathrm{gadd} 45 \mathrm{~b}^{-1-}$ mice. Results indicate normal baseline behaviors and initial learning but enhanced persisting memory in mutants in tasks of motor performance, aversive conditioning and spatial navigation. Furthermore, we showed facilitation of hippocampal long-term potentiation in mutants. These results implicate Gadd45b as a learning-induced gene and a regulator of memory formation and are consistent with its potential role in active DNA demethylation in memory.

\section{Introduction}

Alterations in neuronal gene expression play a necessary role in memory consolidation (Miyashita et al., 2008). Although studies have identified a host of memory-related genes, our understanding of upstream pretranscriptional regulatory processes is incomplete. A growing body of evidence implicates molecular epigenetic mechanisms, which regulate transcription without modifying gene sequences, in memory formation and associated gene transcription (Sultan and Day, 2011). While initial studies focused on histone covalent modifications, a smaller but burgeoning literature similarly uncovered the role of active DNA methylation dynamics in adult memory and synaptic plasticity (Feng et al., 2010). Although de novo hypermethylation has been well characterized, the mechanism of active DNA demethylation, that occurring in the absence of cell division, remains elusive ( $\mathrm{Wu}$ and Zhang, 2010).

Studies implicate the Growth arrest and DNA damageinducible 45 (Gadd45) family in active demethylation (Barreto et al., 2007; Niehrs and Schäfer, 2012), and a landmark study showed Gadd45b mediates gene-specific demethylation in the dentate gyrus following seizure (Ma et al., 2009). These results

Received April 10, 2012; revised 0ct. 3, 2012; accepted 0ct. 5, 2012.

Author contributions: F.A.S. and J.D.S. designed research; F.A.S. and J.W. performed research; J.T. and D.A.L. contributed unpublished reagents/analytic tools; F.A.S. and J.W. analyzed data; F.A.S. wrote the paper.

This work was supported by the NIH (MH095270, MH57014, AG031722, NS057098, P30 NS47466), the Ellison Medical Foundation, the McKnight Brain Research Foundation, and the University of Alabama at Birmingham Neuroscience Molecular Detection Core.

The authors declare no competing financial interests.

Correspondence should be addressed to J. David Sweatt, University of Alabama at Birmingham, Department of Neurobiology, Shelby 1010, 1825 University Boulevard, Birmingham, AL 35294. E-mail: dsweatt@nrc.uab.edu.

DOI:10.1523/JNEUROSCI.1747-12.2012

Copyright $\odot 2012$ the authors $\quad 0270-6474 / 12 / 3217059-08 \$ 15.00 / 0$ along with the finding of activity-induced gadd45b in the hippocampus led us to hypothesize that Gadd45b modulates memory and synaptic plasticity. We tested our hypothesis through molecular studies of experience-dependent gadd45b regulation and behavioral and physiological assessment of gadd $45 b^{-1-} \mathrm{mu}-$ tants. We found selective enhancements in long-term memory and synaptic plasticity in mutants.

\section{Materials and Methods}

Animals and genotyping. Mice for behavioral studies were bred at the University of Alabama at Birmingham. Gadd45b knock-outs on a B6: $129 \mathrm{VJ}$ background were generated as described previously (Gupta et al., 2005). Wild-type and mutant male offspring of heterozygotes between two and 6 months of age were used for behavior and physiology. Animals were singly housed at least $3 \mathrm{~d}$ before the start of experiments. Backcrossed mice were generated by breeding heterozygotes with C57BL/6 wild-types for at least six generations. For expression studies (Fig. $1 A-D$ ), adult male C57BL/6 mice (Harlan) 2-3 months of age were used. Animals were housed under a $12 \mathrm{~h}$ light/dark schedule and provided access to food and water ad libitum. All studies were performed in compliance with the University of Alabama Institutional Animal Care and Use Committee.

Behavioral tasks. Baseline tasks were modified from the work of Chwang et al. (2007). Morris water maze was done as described except that animals first underwent cued training, in which the platform was marked with a visible flag, with four trials per day for $2 \mathrm{~d}$. For hidden training, animals were given four trials per day with a 30 min intertrial interval. Fear conditioning was adapted from Vecsey et al. (2007). For training, after $2 \mathrm{~min}$ of habituation, a tone $(2.8 \mathrm{kHz}, 80 \mathrm{~dB})$ was played for $30 \mathrm{~s}$ and coterminated with a footshock $(0.4 \mathrm{~mA}, 1 \mathrm{~s}$ for mild and $2 \mathrm{~s}$ for moderate training). The animal was removed after an additional $30 \mathrm{~s}$. For robust training, the animal received three such tone-shock pairings $(0.75 \mathrm{~mA}, 2 \mathrm{~s})$ every $2 \mathrm{~min}$ and was removed after a total of $7 \mathrm{~min}$. For 
A

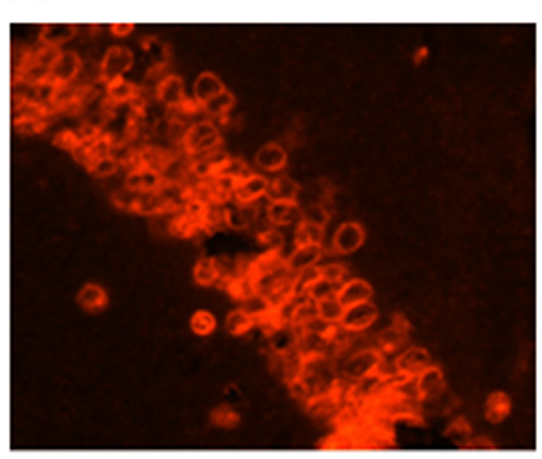

C
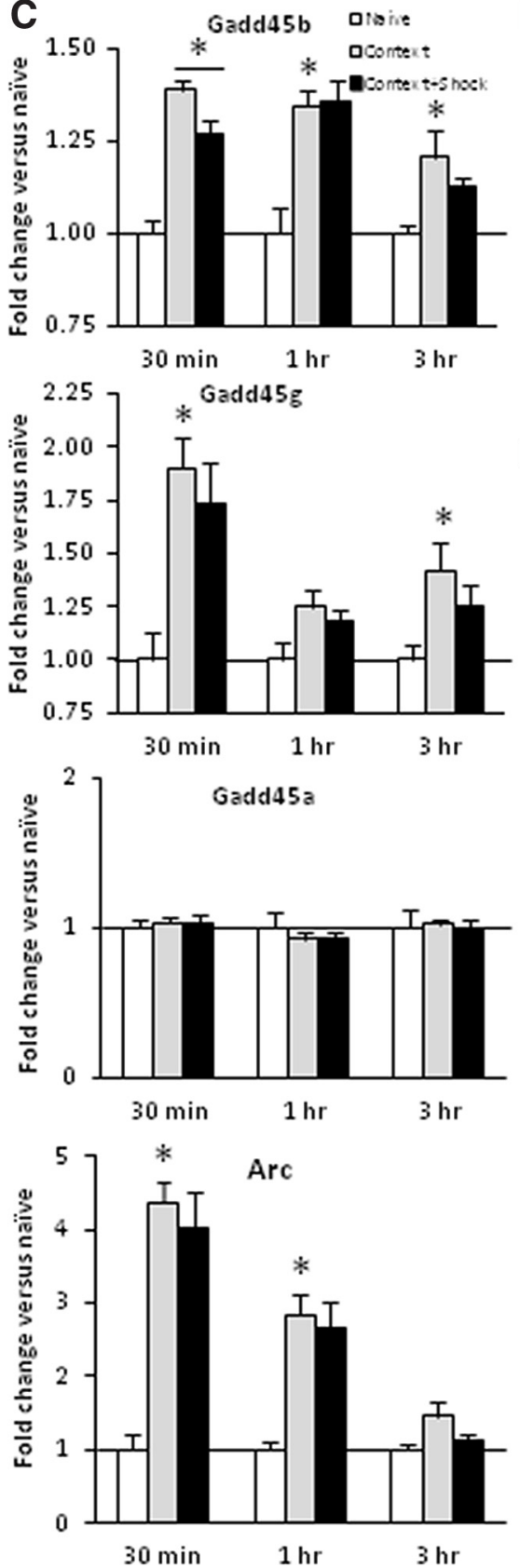

Figure 1. Memory-associated gadd45b transcription. $A$, FISH analysis of gadd $45 b$ expression in area CA1 in naive mouse brain. $B$, Quantitative PCR analysis of gadd45b reveals enrichment in striatum $(p<0.01)$. C, Mice were trained (3 footshock protocol described in Materials and Methods) in contextual fear conditioning (Context + Shock), exposed to the chamber only (Context) or

B
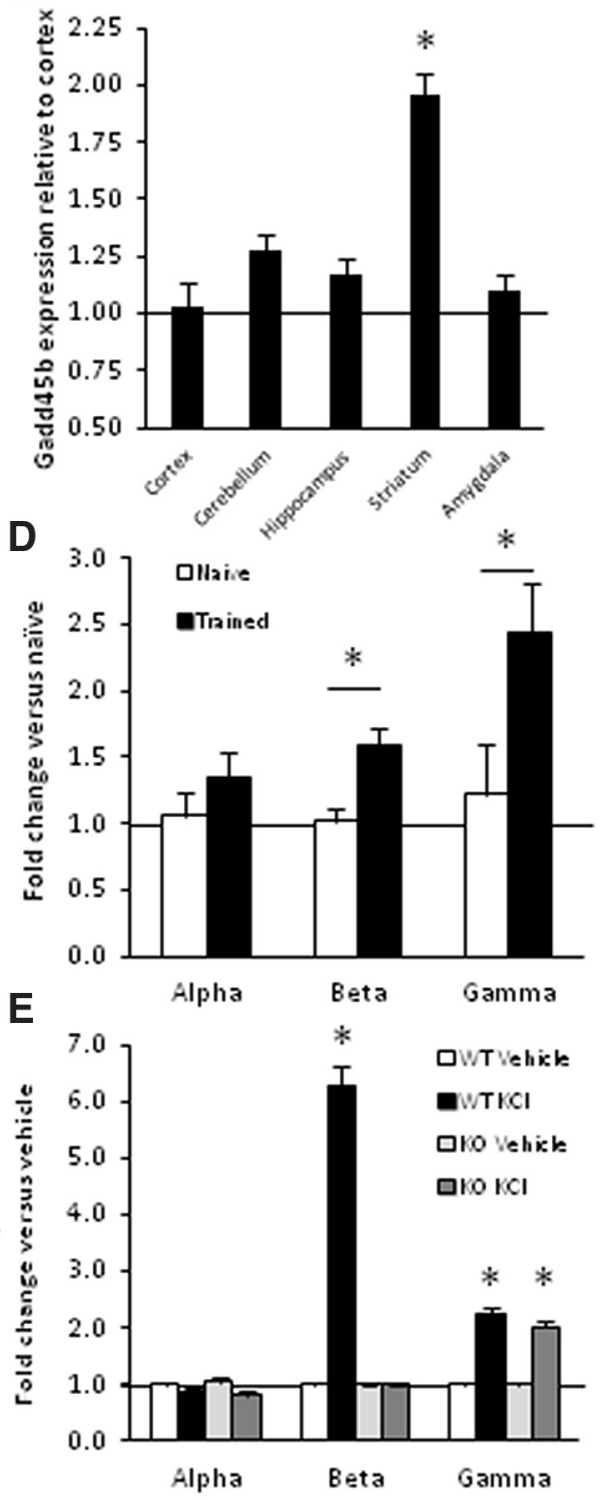

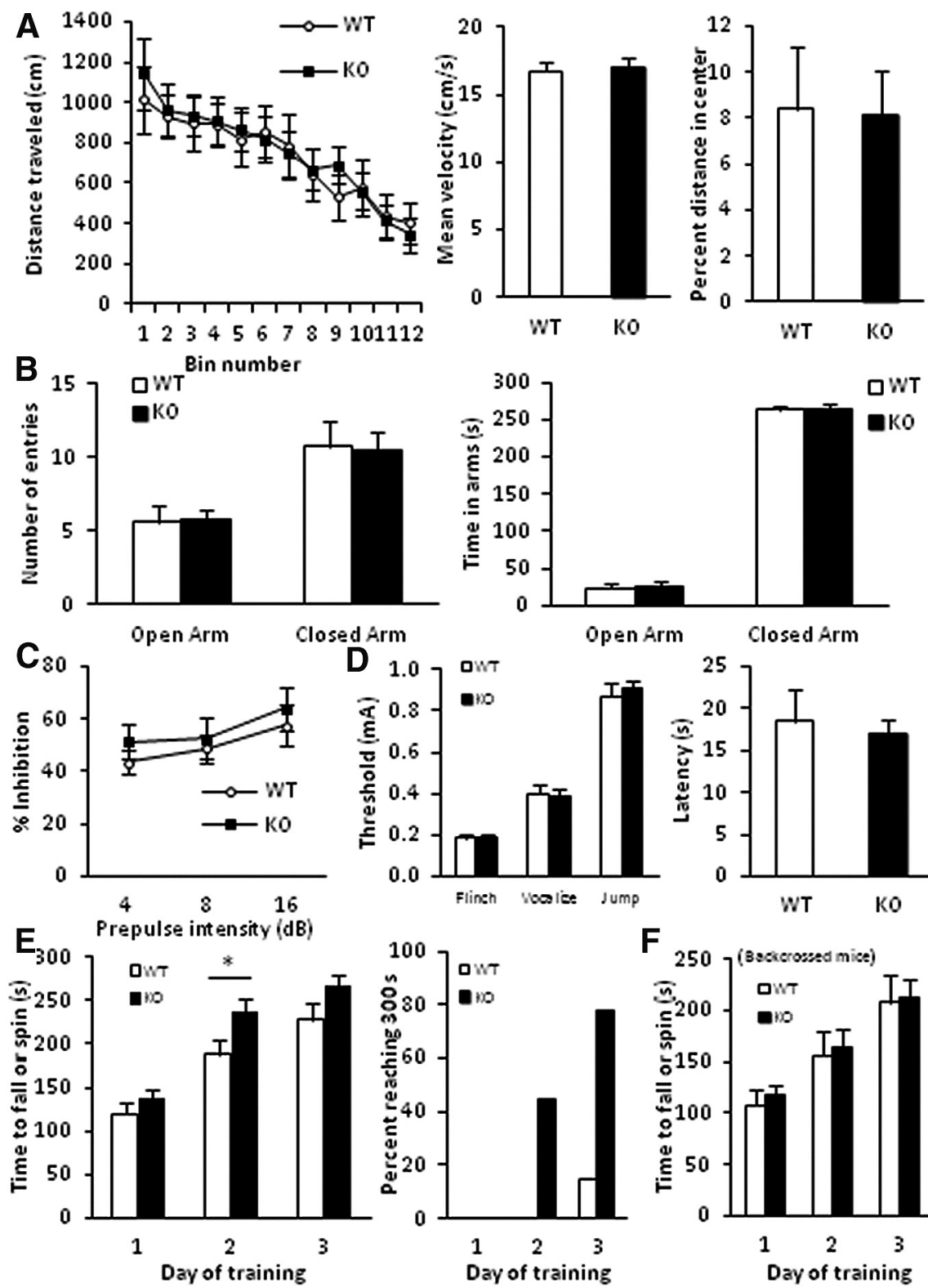

$F$

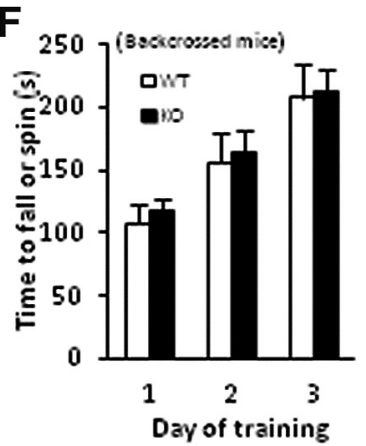

Figure 2. Gadd45 $b^{-1-}$ mutants exhibit normal baseline behavior and elevated motor learning. $\boldsymbol{A}, 0$ pen field. No significant differences were found in horizontal activity (left), velocity (middle) or thigmotaxis (right). $\boldsymbol{B}$, Elevated plus maze. No significant effect of genotype was found on open or closed arm entries (left) or total time spent in open and closed arms (right). C, Prepulse inhibition. No effect of genotype was found at 4, 8 or $16 \mathrm{~dB}$ prepulse intensities. $\boldsymbol{D}$ (Left) Shock threshold test. Similar thresholds to flinch, vocalize and jump were found between genotypes. (Right) Hot plate test. No significant difference in latency to lift or lick the animal's hindpaw was found. $\boldsymbol{E}$, Accelerating rotarod. Mean latency of four trails per day over $3 \mathrm{~d}$ (left) and percentage of animals per genotype reaching 300 s maximum (right) are reported. Knock-outs showed significantly elevated performance on day 2 ( $p<$ $0.05)$. $\boldsymbol{F}$, Accelerating rotarod on backcrossed mice. No significant ( $p>0.05$ ) effect of genotype was found ( $n=7-15 / g r o u p)$.

stimulus intensities $(1-30 \mathrm{mV})$ were used to assess baseline synaptic transmission. Subsequent stimuli were set to an intensity that evoked a field EPSP (fEPSP) that had a slope of $50 \%$ or $25 \%$ of the maximum fEPSP slope. Paired-pulse facilitation (PPF) was measured at various interstimulus intervals $(10-300 \mathrm{~ms})$. Long-term potentiation (LTP) was induced by administering one $100 \mathrm{~Hz}$ tetanus $(0.1-1 \mathrm{~s})$. Synaptic efficacy was assessed for $3 \mathrm{~h}$ following stimulation by recording fEPSPs every $20 \mathrm{~s}$ (traces were averaged for every $2 \mathrm{~min}$ interval). Analysis was performed with two-way ANOVA and unpaired Student's $t$ test.

\section{Results}

Regulation of gadd $45 \mathrm{~b}$ during memory consolidation

To assess gadd $45 b$ transcription in the brain, we first found broad expression of gadd45b in area CA1 (Fig. 1A) and enrichment in the
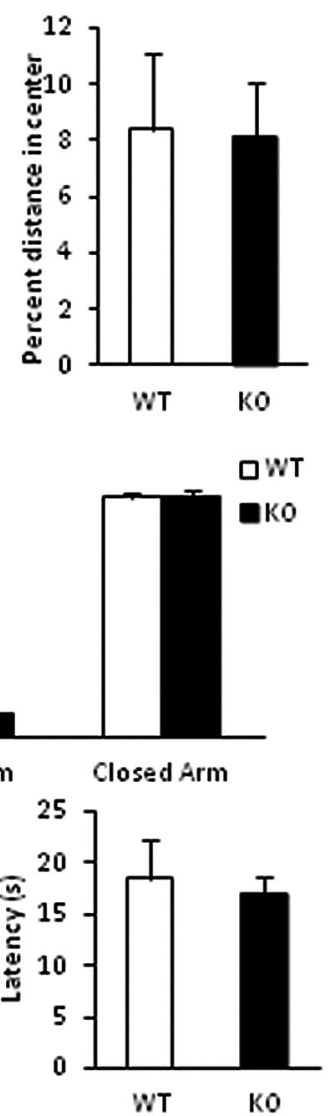

striatum (Fig. $1 B$ ). Seizure activity upregulates expression in the pyramidal and granule cell layers of the hippocampus (Ma et al., 2009), and DNA methyltransferase (DNMT) transcripts are regulated in the hippocampus during memory consolidation (Levenson et al., 2006; Miller and Sweatt, 2007). To determine whether transcription of the gadd45 genes is similarly modulated after fear conditioning, we performed contextual fear conditioning and measured transcripts in area CA1 $30 \mathrm{~min}, 1$ and $3 \mathrm{~h}$ after training. Transcription of gadd $45 b$ was significantly upregulated by both context exposure learning and associative fear training (Fig. 1C). A small but significant reduction in expression was found in the trained group compared with the context group at $30 \mathrm{~min}$. This effect had attenuated by $1 \mathrm{~h}$. Similarly, gadd45g (Gadd45 $\gamma$ ) expression was augmented in the context learning group, but its expression was not further affected by association training. No experience-associated regulation of gadd $45 a$ (Gadd $45 \alpha$ ) was found. Consistent with previous results, arc expression was regulated by activity and not selectively regulated by context-shock association (Huff et al., 2006). In addition, broadly enhanced gadd45b expression in the pyramidal cell layer of CA1 $1 \mathrm{~h}$ after training was confirmed by FISH (data not shown).

Because the amygdala is necessary for fear memory, we assessed gadd45 transcription in the amygdala $1 \mathrm{~h}$ after training and found selective enhancements in gadd $45 b$ and gadd $45 g$ (Fig. 1D). To assess whether gadd $45 b$ ablation affects gadd45a and gadd45g, we cultured hippocampal neurons from wild-type (WT) and knock-out (KO) mice. After depolarization, gadd45b was upregulated in WT neurons, and gadd45g was similarly enhanced in both genotypes (Fig. $1 E$ ). Similar baseline expression of gadd45 $a$ and gadd45g $(p>0.05)$ was also found in gadd $45 b \mathrm{KO}$ and WT neurons (data not shown).

\section{Normal baseline behaviors in

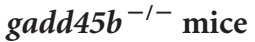

We performed tests to determine whether gadd45b ablation affects baseline behavior. In the open field task, hybrid-background animals were placed in a novel chamber for $1 \mathrm{~h}$. We found no effect on total distance traveled, habituation or mean velocity (Fig. 2A). Additionally, a similar degree of thigmotaxis was found between genotypes. Mutants also exhibited a similar fraction of time in open and closed arms of the elevated plus maze and a similar number of crossings into open arms over a $5 \mathrm{~min}$ period (Fig. 2B). We next performed prepulse inhibition, a test of sensorimotor gating. WT and $\mathrm{KO}$ mice showed robust inhibition upon exposure to prepulses of 4,8 and $16 \mathrm{~dB}$, and no significant effect of genotype were found (Fig. 2C). Since fear conditioning, 
an important memory task, depends on normal perception and response to a mild footshock, two tests of nociception were performed. In the shock threshold task, we found no differences between genotypes in thresholds to flinch, vocalize or jump (Fig. $2 \mathrm{D}$ ). Likewise, normal responses to a $55^{\circ} \mathrm{C}$ surface were found in the hotplate test (Fig. 2D). Backcrossed animals also exhibited no effect of genotype on these tasks (data not shown). These results suggest normal nociception in gadd $45 b^{-1-}$ mice.

We next assessed performance in the accelerating rotarod. Mice were trained over $3 \mathrm{~d}$ with four consecutive trials per day. Day 1 performance is indicative of a rapid phase of motor learning (Bureau et al., 2010). We found no significant differences in mean performance during this phase of learning (Fig. 2E,F). This implies gadd $45 b$ ablation fails to affect short-term motor memory or baseline motor function and coordination. However, $24 \mathrm{~h}$ after training, gadd45 $b^{-1-}$ mice on the hybrid but not C57BL/6 background demonstrated significantly enhanced performance versus wild-types (Fig. 2E,F). Mutants on both backgrounds showed similar performance to wild-types on day 3 . However, a ceiling effect may have masked augmented performance by hybrid-background knock-outs, as a larger fraction of these mice reached the $300 \mathrm{~s}$ ( $40 \mathrm{rpm}$ ) maximum on days 2 and 3 (Fig. 2E). These results implicate gadd $45 b$ in motor memory consolidation but not initial acquisition.

\section{Enhanced hippocampus-dependent memory in $\operatorname{gadd}_{45} \mathrm{~b}^{-1-}$ mice}

Active DNA demethylation has been documented in the consolidation of hippocampus-dependent memory (Day and Sweatt, 2010). In light of the function of Gadd45b in this molecular process, we sought to determine the cognitive effects of its deletion. In cue-plus-context fear conditioning, the rodent learns in a single-trial training session to associate a novel context and auditory cue with a mild footshock. We trained WT and KO hybridbackground mice with mild, moderate and robust paradigms and reexposed them to the chamber 1 or $24 \mathrm{~h}$ later to assess shortterm and long-term contextual fear memory. Significantly enhanced performance of $\mathrm{KO}$ compared with WT mice was found at $24 \mathrm{~h}$ with mild and moderate but not robust training (Fig. $3 \mathrm{~A}$ ). Normal acquisition and short-term memory were found with moderate training (Fig. 3B). Both genotypes also exhibited normal and similar extinction learning (Fig. 3C). Since dynamic modulation of DNA methylation has also been associated with remote memory (Miller et al., 2010), we assessed contextual fear memory $28 \mathrm{~d}$ after modified mild training and found significantly enhanced freezing in knock-outs (Fig. 3D). We next confirmed the enhanced memory consolidation phenotype in backcrossed knock-out mice (Fig. 3E). Similar performance between genotypes was found in short-term memory assessment.

Since contextual fear memory relies on intact functioning of the hippocampus and amygdala, we next tested memory for the cue-shock association, a hippocampus-independent process. We found no significant effect of genotype during cued testing in hybrid-background animals (Fig. $3 F$ ).

We next trained mice in the Morris water maze, a measure of spatial learning and memory. Animals were first trained in the cued version of the task, in which the submerged platform was demarcated by a visible flag. Although wild-type and mutant mice successfully learned the task within $1 \mathrm{~d}$ and showed robust performance on the second day, gadd $45 b^{-1-}$ mice showed significantly enhanced latencies on the first 3 trials (Fig. 3G). During the hidden platform task, no significant differences were found in latencies to locate the escape, sug- gesting normal acquisition of spatial memory. Performance on the first probe trial indicated that $g a d d 45 b^{-1-}$ rodents crossed the platform location significantly more times than gadd $45 b^{+/+}$mice. After the last training session, a second probe trial was administered; no differences were found in platform crossings. Additionally, animals of each genotype showed similar $(p>0.05)$ swim speeds during training and probe trials (data not shown). Backcrossed mice demonstrated no effect of genotype on cued or hidden platform training (data not shown) but significantly enhanced platform crossings on the first but not second probe trial (Fig. $3 H$ ).

\section{Enhanced hippocampal synaptic plasticity in gadd $45 b^{-/-}$mice}

Lasting synaptic plasticity supports memory consolidation (Sweatt, 2010). To determine whether the memory-augmenting effect of gadd $45 b$ deletion correlated with enhanced synaptic plasticity, we measured activity-induced LTP ex vivo in area CA1 induced by stimuli of varying strength. A significant enhancement in latephase LTP was found after stimulation with a near-threshold stimulus (Fig. 4A). No differences were found in LTP magnitude when slices were stimulated by $100 \mathrm{~Hz}$ pulses with normal intensities (Fig. 4B-D). Normal baseline synaptic transmission was found in input-output studies (Fig. $4 E$ ). Surprisingly, a significant effect of genotype was found in paired-pulse facilitation induced by low- but not normal-intensity stimulation (Fig. 4F, G). Knock-out slices exhibited small but significant deficits in PPF at interstimulus intervals of 250 and $300 \mathrm{~ms}$.

\section{Discussion}

We verified that gadd $45 b$ is dynamically tuned during memory formation and that gadd45b deletion facilitates memory and synaptic plasticity. Expression data show gadd45b is widely expressed in the adult brain and undergoes rapid, activitydriven transcription in the hippocampus and amygdala (Fig. 1). Gadd $45 b^{-1-}$ neurons do not show compensatory regulation of other gadd45 isoforms and show normal induction of gadd $45 \mathrm{~g}$ by activity (Fig. $1 \mathrm{E}$ ). Additionally, gadd45b exhibits selective, memory-associated suppression during fear memory formation, suggesting it may act as a negative memory regulator (Fig. 1C). In contrast, $d n m t 3 a$ and $d n m t 3 b$ are enhanced by context-shock association in the same training paradigm, and inhibition of DNMT function impairs memory (Miller and Sweatt, 2007; Feng et al., 2010). These results are not surprising in light of the opposing function of these epigenetic regulators (although DNMTs have paradoxically also been implicated in DNA demethylation) (Métivier et al., 2008). Consistent with this interpretation, behavioral assessment of gadd $45 \mathrm{~b}$ mutants showed no effects on baseline function and enhanced consolidation of motor memory and hippocampus-dependent contextual memory (Figs. 2, 3). This memory augmentation was first observed $24 \mathrm{~h}$ after training and persisted for $28 \mathrm{~d}$. Normal performance of mutants in a hippocampus-independent cued fear memory task suggests Gadd45b does not contribute to amygdala-dependent learning (Fig. 3F).

Our data demonstrate selective enhancement of late-phase LTP magnitude in knock-out hippocampi upon induction by near-threshold stimulus (Fig. $4 A-D$ ). These data are highly consistent with fear conditioning data which show the most robust phenotypes following modest fear conditioning training (Fig. $3 A-E)$. Additionally, mutants performed better on the first Mor- 
A
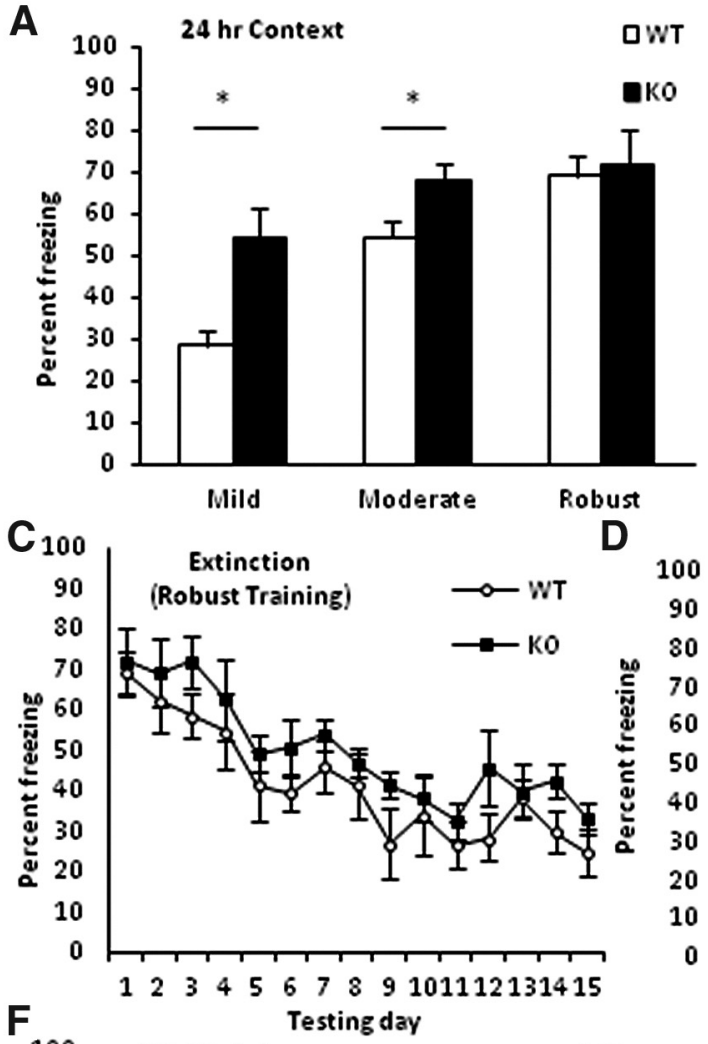

D 100
B
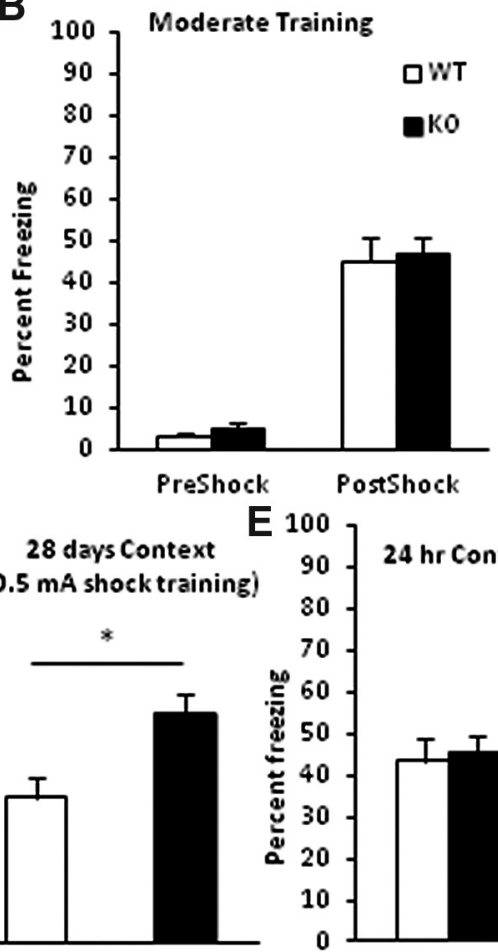

KO

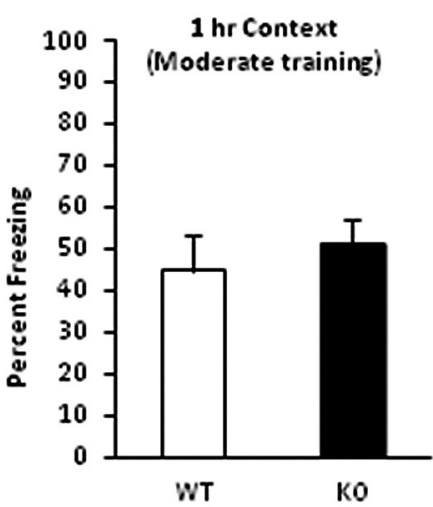

(Backcrossed mice)
0

24 hr Context 24 hr Context 1 hr Context
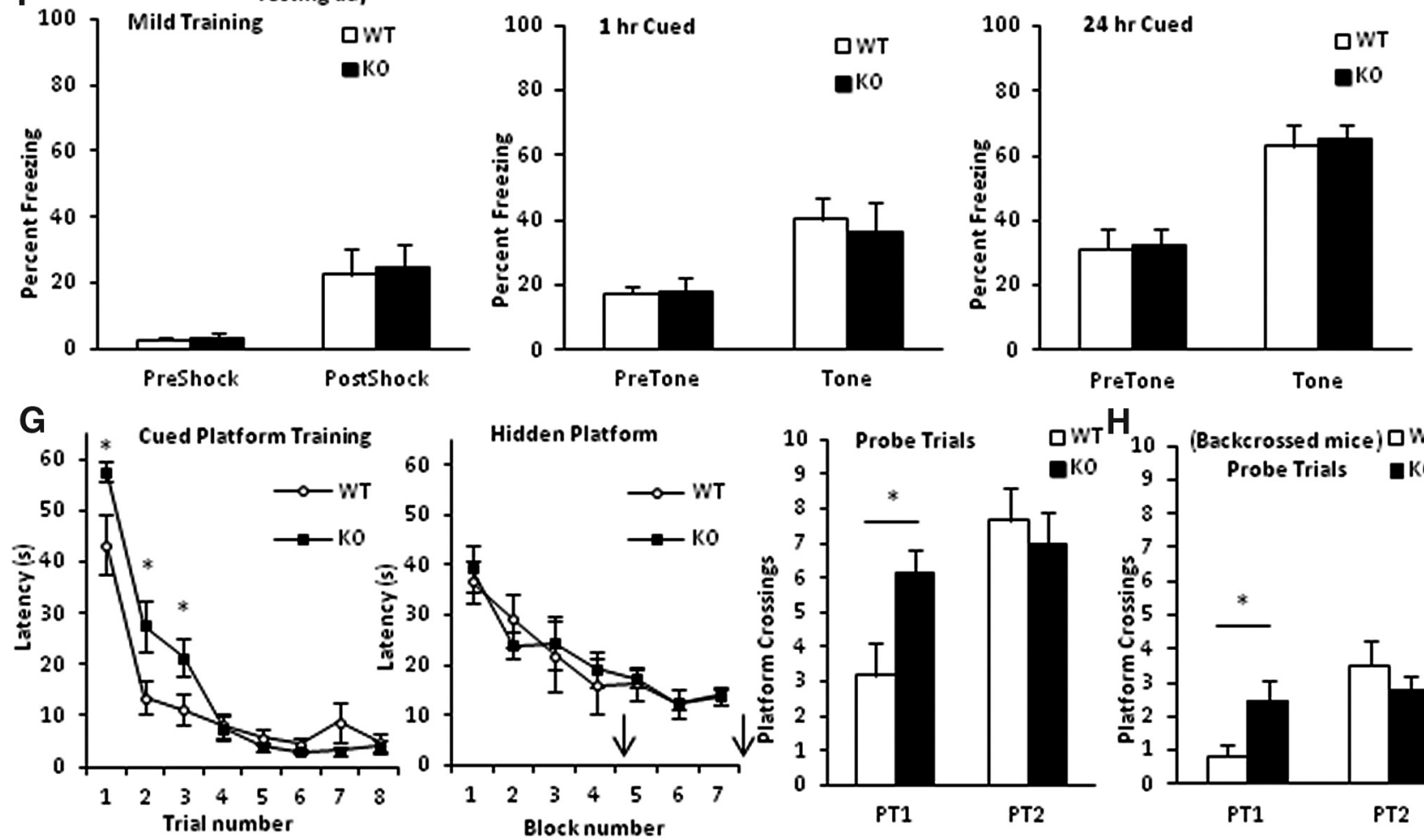
$\left.\begin{array}{c}\mathrm{H}_{10} \\ 9\end{array}\right] \begin{gathered}\text { (Backerossed mice) } \\ \text { Probe Trials }\end{gathered}$

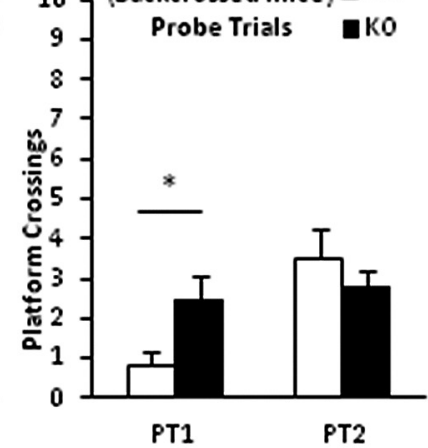

Figure 3. Enhanced long-term memory in gadd $45 b^{-1-}$ mice. $A$, Mice were trained with mild, moderate and robust cue-plus-context fear conditioning paradigms and returned to the training chamber in the absence of a footshock after $24 \mathrm{~h}$. Knock-outs exhibited significantly higher percentage freezing $(p<0.05)$ after mild and moderate but not robust training. $\boldsymbol{B}$, Mice trained with the moderate paradigm were tested for contextual memory at $1 \mathrm{~h}$. No significant effects of genotype were found during training (left) or testing (right). $C$, Mice trained with the robust paradigm underwent extinction training for $15 \mathrm{~d}$. Both genotypes exhibited significant fear extinction $(p<0.05)$. No main effect of genotype was found $(p>0.05)$. D, Mice trained with a modified mild paradigm with $0.5 \mathrm{~mA}$ shock were tested for contextual memory at $28 \mathrm{~d}$. Mutants showed significantly $(p<0.05)$ higher freezing. $E$, Backcrossed mice were trained with modified mild paradigm ( 0.5 or $0.3 \mathrm{~mA}$ shock) and tested after 1 or $24 \mathrm{~h}$. Mutants exhibited normal short-term memory and significant $(p<0.05)$ enhancement in long-term memory only after $0.3 \mathrm{~mA}$ shock training. $\boldsymbol{F}$, Hybrid-background mice were trained with the mild paradigm and tested 1 or $24 \mathrm{~h} \mathrm{later} \mathrm{in} \mathrm{a} \mathrm{novel} \mathrm{context} \mathrm{for} \mathrm{tone-shock} \mathrm{association.} \mathrm{No} \mathrm{effect} \mathrm{of} \mathrm{genotype}(p>0.05)$ was found. $\mathbf{G}$, Morris water maze. Hybrid-background knock-outs exhibited significant $(p<0.05)$ deficits in the cued visible platform task and similar $(p>0.05)$ performance to wild-types during hidden platform training. Probe trials, denoted by arrows, were given at the beginning of days 5 and 8 . Mutants also demonstrated augmented performance in the first but not second probe trial (right, $p<0.05)$. $\boldsymbol{H}$, Backcrossed mutants trained similarly showed enhanced performance to wild-types on the first but not second probe trial $(p<0.05)(n=6-15 /$ group). 
ris water maze probe trial, but both genotypes showed robust performance on the second trial (Fig. 3G,H).

Gadd $45 b^{-1-}$ hippocampal slices surprisingly show PPF deficits at long interstimulus intervals (Fig. 4G), suggesting presynaptic mechanisms may be altered. Mutants may have reduced residual calcium following low-intensity activation. Alternatively, mutants may experience reduced function of proteins mediating short-term plasticity such as NCS-1 (Jeromin et al., 2006). Transcription of genes supporting each of these mechanisms may be subject to epigenetic regulation by Gadd45b whose net activity may predominate at lower activity. Although mutant slices exhibit this difference in short-term plasticity, this finding is still consistent with the lack of observed phenotypes in tasks of short-term memory, as current models do not posit a role for short-term plasticity on the millisecond time scale as underlying short-term memory in the 1-2 h time frame (Sweatt, 2010).

The finding that mutants exhibit selective long-term memory phenotypes but normal learning is consistent with an epigenetic hypothesis, as de novo transcription modulates the former but not latter phase. Gadd45b has been shown to modulate activity-associated DNA demethylation (Ma et al., 2009) and, during memory formation, may similarly target loci such as reelin and bdnf (Day and Sweatt, 2010). Of note, Gadd45b binds these loci upon mGlu2/3 receptor activation, an antipsychotic pharmacological paradigm associated with demethylation (Matrisciano et al., 2011). Still, impairments in demethylation and transcriptional upregulation of these memory-enhancing transcripts would suggest cognitive impairments in mutants. However, the breadth of demethylation target loci is unknown. In particular, mutants may also experience heightened hypermethylation and downregulation of memory-suppressor genes such as $P P 1 \beta$ and calcineurin (Miller and Sweatt, 2007; Miller et al., 2010). Similarly, mGlu2/3 activation enhanced Gadd45b binding to and demethylation of $G A D 67$, a regulator of inhibitory tone (Matrisciano et al., 2011). Alternatively, Gadd45b may modulate expression of other epigenetic regulators including DNMTs and numerous histone-modifying enzymes. It is also possible that active neurogenesis may regulate the memory phenotype, but this appears unlikely because of the long time scale needed for cell maturation and integration into the hippocampal circuit and because neurogenesis has been positively, not negatively, linked to cognition (Ma et al., 2009; Koehl and Abrous, 2011). Additionally, we can-
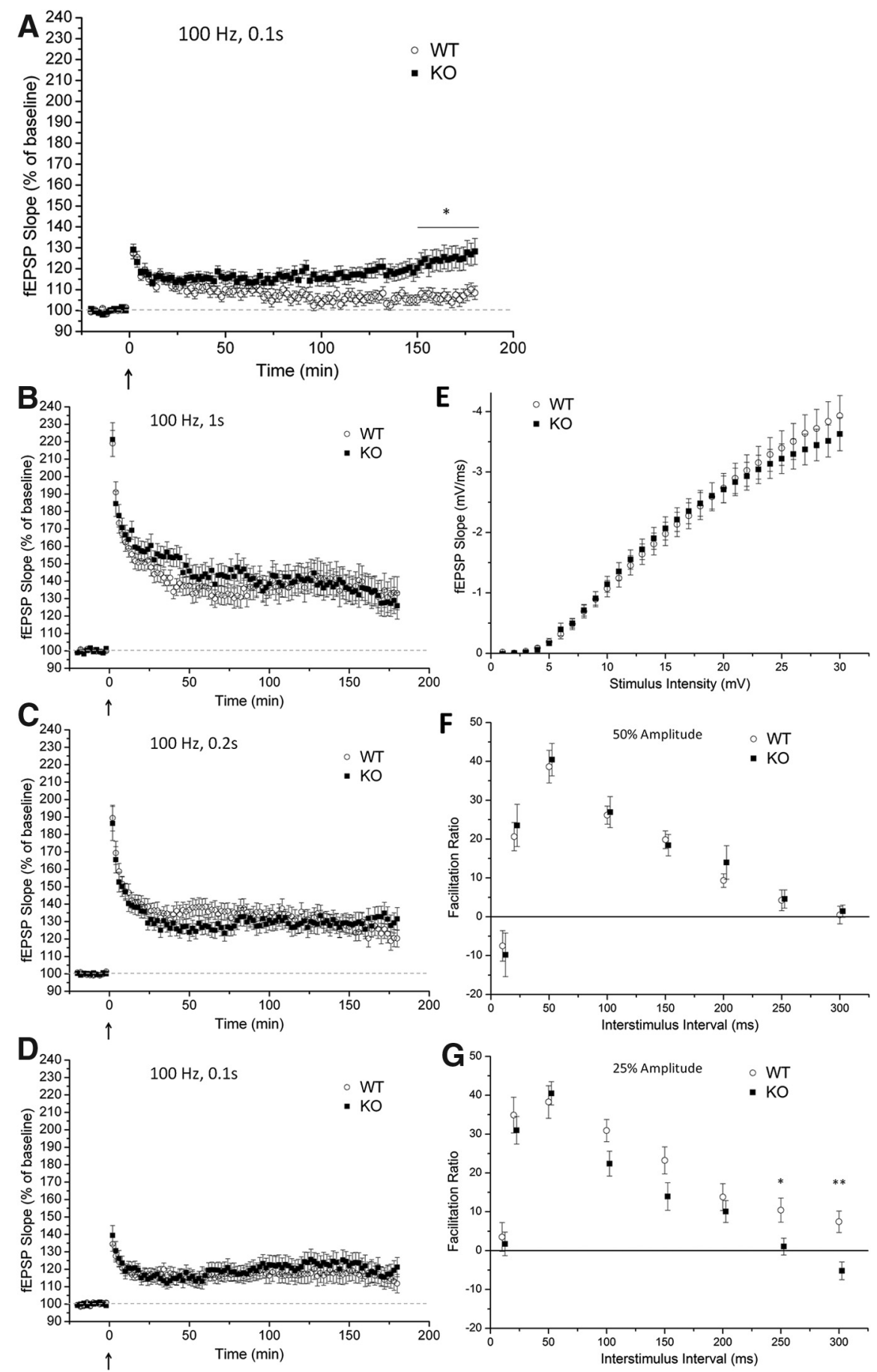

Figure 4. Facilitation of long-term potentiation in gadd $45 b^{-1-}$ mutants. $A-D$, Field EPSP recordings from area CA1 before and after stimulation of Schaffer collaterals with listed paradigms. Stimuli were set to an intensity eliciting a fEPSP with $25 \%$ of the maximum slope in $\boldsymbol{A}$ and $50 \%$ in $\boldsymbol{B}-\boldsymbol{D}$. Mutant slices demonstrated enhanced LTP $(p<0.05)$ during the last 30 min of recording only after low-intensity induction. $\boldsymbol{E}$, Input-output relationship of evoked fEPSP slope versus stimulus intensity in WT and $K 0$ slices revealed no effect of the mutation on baseline synaptic transmission. $F, G$, Paired-pulse facilitation studies across different interstimulus intervals revealed no effect of genotype when using normal-intensity stimuli $(\boldsymbol{F})$ but a significant $(p<0.01)$ deficit in KOs under low-intensity stimuli (G) ( $n=6-15$ mice/group, $4-10$ slices/mouse).

not discount the possible role of numerous non-epigenetic signaling factors mediated by Gadd45b (Papa et al., 2004).

In addition, we note that near-threshold slice stimulation produced relatively stable LTP for $\sim 2 \mathrm{~h}$ following the tetanus and that field slopes appeared to ramp up slightly for the next $1 \mathrm{~h}$ (Fig. 
$4 A$ ). This surprising result suggests Gadd $45 \mathrm{~b}$ may play a role not only in the stabilization of potentiated synaptic weights but also in the long-term stability of these weights. Potentially, stimulation may initiate a cascade of epigenetic reprogramming events in the neuron which influence distinct rounds of target gene expression, and novel protein products may affect different components of LTP maintenance. Identification of these epigenetically modulated gene products will be the subject of future investigations into the breadth of the complex, temporally and regionally defined epigenomic interactome within the memory-subserving neuron.

We note that enhanced remote memory in mutant mice (Fig. $3 D$ ) indicates the persisting effect of $g a d d 45 b$ deletion on memory retention. This finding implies cortical epigenetic mechanisms, perhaps distinct from those in the hippocampus, may be influenced by Gadd45b in the storage of lasting fear memory. Indeed, DNA methylation has been shown to subserve memory storage in the anterior cingulate cortex (Miller et al., 2010). However, this finding may alternatively result from "spillover" from enhanced consolidation of fear memory in the hippocampus.

While Gadd45b is necessary for seizure-induced demethylation of $b \operatorname{dnf}$ (Ma et al., 2009), this does not rule out the possibility that Gadd45g or Gadd45a play overlapping roles with Gadd45b in regulating other loci. This possibility may explain why mutants respond similarly to wild-types upon robust behavioral and synaptic experience. Gadd45b-mediated mechanisms may predominate at lower activity, leading to the near-threshold phenotypes observed. This hypothesis is consistent with the finding that context-shock association appears to suppress gadd $45 \mathrm{~b}$ induction in CA1 shortly after training (Fig. 1C). It is possible that, before onset of the fear memory consolidation window, the neuron modulates its epigenetic tone to promote methylating and reduce demethylating activity and that it achieves this in part by attenuating Gadd45b function. Although mRNA induction does not appear to vary between trained and context-only control mice $1 \mathrm{~h}$ after foreground conditioning, overall demethylation function could still be modulated by other means such as translational regulation of Gadd45b. While the mechanism of demethylation is not known, it is unlikely that Gadd $45 \mathrm{~b}$ acts alone in this process; rather, the orchestrated activity of a number of demethylation regulators is probably necessary, and the interaction of Gadd $45 \mathrm{~b}$ with these proteins may be differentially regulated during memory consolidation (Rai et al., 2008; Wu and Zhang, 2010; Guo et al., 2011).

We finally note that one of our results conflicts with those of the recently published Leach et al. (2012) manuscript. Our findings are consistent with those of this study regarding experience-dependent regulation of gadd $45 b$ transcription and a lack of phenotype in cued fear conditioning. However, Leach et al. (2012) observed a deficit in contextual fear conditioning whereas we observed an enhancement using nearthreshold training stimulation. The reasons for these differing observations are not clear; one possibility is subtle background strain differences that may have arisen during backcrossing. Indeed, we feel that a parsimonious explanation is that effects of the loss of a potent regulator of the epigenome such as gadd45b might be exquisitely sensitive to both the background genome in which the gene product resides and the prior experiential history of the animals under study. In light of the prolific role of context-dependent epigenetic tuning of animal behavior by experience, it is possible that differences in the housing or training facility environments may have amplified subtle differences in background genome or epigenome in mutant mice (Crews, 2011). Additionally, Leach et al. (2012) used a foreground training paradigm for contextual memory assessment whereas our study predominantly used background training. Regardless, our studies and those of Leach et al. (2012) are consistent with the hypothesis that gadd45b is transcriptionally regulated by experience and also regulates memory capacity.

In conclusion, these results suggest Gadd $45 \mathrm{~b}$ and potentially other modulators of DNA demethylation regulate memory function and may be viable therapeutic targets in cognitive disease.

\section{References}

Barreto G, Schäfer A, Marhold J, Stach D, Swaminathan SK, Handa V, Döderlein G, Maltry N, Wu W, Lyko F, Niehrs C (2007) Gadd45a promotes epigenetic gene activation by repair-mediated DNA demethylation. Nature 445:671-675. CrossRef Medline

Bureau G, Carrier M, Lebel M, Cyr M (2010) Intrastriatal inhibition of extracellular signal-regulated kinases impaired the consolidation phase of motor skill learning. Neurobiol Learn Mem 94:107-115. CrossRef Medline

Chwang WB, Arthur JS, Schumacher A, Sweatt JD (2007) The nuclear kinase mitogen- and stress-activated protein kinase 1 regulates hippocampal chromatin remodeling in memory formation. J Neurosci 27: 12732-12742. CrossRef Medline

Crews D (2011) Epigenetic modifications of brain and behavior: theory and practice. Horm Behav 59:393-398. CrossRef Medline

Day JJ, Sweatt JD (2010) DNA methylation and memory formation. Nat Neurosci 13:1319-1323. CrossRef Medline

Feng J, Zhou Y, Campbell SL, Le T, Li E, Sweatt JD, Silva AJ, Fan G (2010) Dnmt1 and Dnmt3a maintain DNA methylation and regulate synaptic function in adult forebrain neurons. Nat Neurosci 13:423-430. CrossRef Medline

Guo JU, Su Y, Zhong C, Ming GL, Song H (2011) Hydroxylation of 5-methylcytosine by TET1 promotes active DNA demethylation in the adult brain. Cell 145:423-434. CrossRef Medline

Gupta M, Gupta SK, Balliet AG, Hollander MC, Fornace AJ, Hoffman B, Liebermann DA (2005) Hematopoietic cells from Gadd45a- and Gadd45b-deficient mice are sensitized to genotoxic-stress-induced apoptosis. Oncogene 24:7170-7179. CrossRef Medline

Huff NC, Frank M, Wright-Hardesty K, Sprunger D, Matus-Amat P, Higgins E, Rudy JW (2006) Amygdala regulation of immediate-early gene expression in the hippocampus induced by contextual fear conditioning. J Neurosci 26:1616-1623. CrossRef Medline

Jeromin A, Rosa P, Sharma Y, Tsujimoto T (2006) Neuronal calcium sensor-1 (NCS-1) as a multi-functional regulator of lipids and channels. Calcium Binding Proteins 1:16-19.

Koehl M, Abrous DN (2011) A new chapter in the field of memory: adult hippocampal neurogenesis. Eur J Neurosci 33:1101-1114. CrossRef Medline

Leach PT, Poplawski SG, Kenney JW, Hoffman B, Liebermann DA, Abel T, Gould TJ (2012) Gadd45b knockout mice exhibit selective deficits in hippocampus-dependent long-term memory. Learn Mem 19:319324. CrossRef Medline

Levenson JM, Roth TL, Lubin FD, Miller CA, Huang IC, Desai P, Malone LM, Sweatt JD (2006) Evidence that DNA (cytosine-5) methyltransferase regulates synaptic plasticity in the hippocampus. J Biol Chem 281:1576315773. CrossRef Medline

Ma DK, Jang MH, Guo JU, Kitabatake Y, Chang ML, Pow-Anpongkul N, Flavell RA, Lu B, Ming GL, Song H (2009) Neuronal activity-induced Gadd45b promotes epigenetic DNA demethylation and adult neurogenesis. Science 323:1074-1077. CrossRef Medline

Matrisciano F, Dong E, Gavin DP, Nicoletti F, Guidotti A (2011) Activation of group II metabotropic glutamate receptors promotes DNA demethylation in the mouse brain. Mol Pharmacol 80:174-182. CrossRef Medline

Métivier R, Gallais R, Tiffoche C, Le Péron C, Jurkowska RZ, Carmouche RP, Ibberson D, Barath P, Demay F, Reid G, Benes V, Jeltsch A, Gannon F, Salbert G (2008) Cyclical DNA methylation of a transcriptionally active promoter. Nature 452:45-50. CrossRef Medline

Miller CA, Sweatt JD (2007) Covalent modification of DNA regulates memory formation. Neuron 53:857-869. CrossRef Medline 
Miller CA, Gavin CF, White JA, Parrish RR, Honasoge A, Yancey CR, Rivera IM, Rubio MD, Rumbaugh G, Sweatt JD (2010) Cortical DNA methylation maintains remote memory. Nat Neurosci 13:664-666. CrossRef Medline

Miyashita T, Kubik S, Lewandowski G, Guzowski JF (2008) Networks of neurons, networks of genes: an integrated view of memory consolidation. Neurobiol Learn Mem 89:269-284. CrossRef Medline

Niehrs C, Schäfer A (2012) Active DNA demethylation by Gadd45 and DNA repair. Trends Cell Biol 22:220-227. CrossRef Medline

Papa S, Zazzeroni F, Bubici C, Jayawardena S, Alvarez K, Matsuda S, Nguyen DU, Pham CG, Nelsbach AH, Melis T, De Smaele E, Tang WJ, D’Adamio L, Franzoso G (2004) Gadd45 beta mediates the NF-kappa B suppression of JNK signalling by targeting MKK7/JNKK2. Nat Cell Biol 6:146-153. CrossRef Medline
Rai K, Huggins IJ, James SR, Karpf AR, Jones DA, Cairns BR (2008) DNA demethylation in zebrafish involves the coupling of a deaminase, a glycosylase, and gadd45. Cell 135:1201-1212. CrossRef Medline

Sultan FA, Day JJ (2011) Epigenetic mechanisms in memory and synaptic function. Epigenomics 3:157-181. CrossRef Medline

Sweatt JD (2010) Mechanisms of memory. Burlington, MA: Elsevier.

Vecsey CG, Hawk JD, Lattal KM, Stein JM, Fabian SA, Attner MA, Cabrera SM, McDonough CB, Brindle PK, Abel T, Wood MA (2007) Histone deacetylase inhibitors enhance memory and synaptic plasticity via CREB:CBP-dependent transcriptional activation. J Neurosci 27: 6128-6140. CrossRef Medline

Wu SC, Zhang Y (2010) Active DNA demethylation: many roads lead to Rome. Nat Rev Mol Cell Biol 11:607-620. CrossRef Medline 